\title{
Training-performance relationship: A Study of Nepalese Banking Sector
}

\author{
Dr. Dhruba Lal Pandey ${ }^{1}$
}

\begin{abstract}
Training is one of the dominant techniques of management development program in modern organizations. Substantial number of studies on human resource management literature focuses the relationship between training and employee performance with its broader implication on organizational growth and profitability particularly the training effect in gaining sustained competitive advantages. This study aims to test the hypothesized relationship of training and organizational performance in Nepalese banking sector. A survey design approach was applied. Ten commercial banks were selected randomly and 230 respondents from various banks participated in the survey. Likert scale questions were used for getting responses. Multiple regression analysis, ANOVA, and simple descriptive statistics were used for data analysis. All training techniques taken individually and in group (formal, informal) were regressed on turnover growth. The study result confirmed that the both incidence and intensity of training has strong effect on organizational performances particularly the turnover growth. Interestingly the study found that the firms investing predominantly in formal training better performed than those relying on informal training. However, the firm size, organization structure and technology have moderating effect on training-performance relationship stressing for requisites of further research to confirm the cross sectional validity of findings rather than to its early generalizations.
\end{abstract}

Key words: training, performance, turnover growth, business survival, firm size, technology

\section{Introduction}

The general assumption is that those businesses that pay more attention to training and development will be more successful in the long run and their performance increases, which helps to gain sustained competitive advantages. This assumption supports the substantial investment in training by various agencies (Devins and Johnson, 2003) and governments of different countries (Storey, 2004). Although this claim is widely accepted but the evidences show that training and management development's impact on enhancing performance is difficult to explain (Storey and Westhead, 1994; Storey, 2004). A large body of the training literature has attempted to address this issue by empirically testing the relationship between training investments - both in terms of resources and time - and firm performance through individual and firm level data. Several recent reviews, however, have shown that the empirical evidence for training influence on firm performance is generally inconsistent and inconclusive ( Storey, 1994; Morgan et al., 2002; Heraty and Morley, 2003; Storey, 2004).

On the other hand, those who provide a more positive link to the relationship found that training could

1 Lecturer, Central Department of Management, T.U. 
facilitate a firm's expansion (Cosh et al., 1998), existence (Marshall et al., 1995), profitability and productivity (Betcherman et al., 1997) and competitive advantage (Huang, 2001; Smith and Whittaker, 1999). Jennings and Banfield (1993) claimed that "training can, and should be a powerful agent of change, facilitating and enabling a company to grow, expand and develop its capabilities thus enhancing profitability". Huang (2001) suggests that firms with sophisticated training systems and strong management support for training have effective training programmes and are more successful in delivering training. Hallier and Butts (1999) stated that organisational performance can be held back through a neglect of training activity. In their impact assessment study, Marshall et al. (1993) found that government funded training investments in banking have significant influence in setting proactive strategies to combat recession; 50 per cent of receiving companies as compared to 12 per cent of the control group increased employment opportunities, increased investments and had a perception of resultant increased profit.

Therefore, the training literature has provided contradictory evidence. Although there are some clear examples of how training influences firm success, it is suggested that this contradictory evidence discourages both policy makers and banking managers in their attempts to be more proactive within the area of management development and training (Marshall et al., 1993; 1995; Patton et al., 2000). Cushion (1995) and Kerr and McDougall (1999) link this problem to the lack of effective evaluation of management training in banking organizations. Issues such as short time horizons (Westhead and Storey, 1996), lack of appropriate and holistic measures for banking organizations (Hannon, 1999; Cushion, 1995 and the difficulties in establishing causal links between training and performance (Storey, 1994) mitigate against effective evaluation of training outcomes. However, it is argued that checking correlations between key variables to establish patterns of behaviour is more important than determining causal relationship between training and performance (1994). One of the primary focuses of this study, therefore, is filling this gap through an in-depth analysis of the training-performance relationship.

\section{Factors Influencing Training Approach}

Researchers agree that banking training is essentially informal and reactive response to short-term issues (Hill and Stewart, 2000). To face external uncertainty, banking organizations prefer to take flexible routes (Westhead and Storey, 1996). Further, the Skill Assessment Banking Report (2002) noted that resourcescarce banking managers believe informal approaches provide cost-effective solutions. Given the importance of informal training to the banking sector, it is perhaps surprising that existing research focuses almost exclusively on the effects and outcomes of formal training programmes. This presents a significant research gap.

While highlighting the critical need for proper measures for training constructs, Kitching and Blackburn (2002) noted that the mismatch between firm practice and research focus is something that needs immediate attention. A broad definition of training includes any attempt, within or outside the organisation, to increase job-related knowledge and skills of either managers or employees (Kitching and Blackburn, 2002). Although this definition captures important parameters, the Skills Assessment Banking Report (2002) 
also emphasises specifically the need to distinguish between formal and informal training approaches. Training itself is a difficult concept to quantify, but Westhead (1998) believes that the practice of providing sweeping generalisations to cover a variety of cases that are in many ways dissimilar makes things even more confusing. Thus, this study makes a clear distinction between formal and informal training practices. Formal training and development is defined as "initiatives which can be identified by both recipients and deliverers as an intervention which has a structured mode of delivery, where the aim is to impart new awareness or knowledge of a workplace process or activity" (Patton and Marlow, 2002). We define informal training initiatives as ad-hoc, fragmented and flexible. Such initiatives depend on the environment of the organisation, the nature of the task in hand, the propensity of individuals to learn, and lack a formal structure and stated objectives. Training practices in the study are defined against these criteria.

Banking training research often considers the provision of training at individual level with staff/employee education and training receiving attention over management training and development. O'Dwyer and Ryan (2000) argue that banking training researchers should focus on management training and education, as it is an area that is critical for firm success, but receives no special attention. Therefore, this study considers management training at the firm level. However, in contrast to other firm level studies, this study does not take the amount of time or money spent on training as measures for training commitment. Reflecting the need to identify actual patterns of behaviour, we use the number and type of practical interventions undertaken by a firm as indicators for training investment.

Finally, existing work rarely considers the factors that determine the level and provision of training. Hannon (1999) in a summary of the literature on training and management development processes in banking sector, refers to management within banking organizations as situationally specific, and dependent on a variety of factors such as leadership roles, product or market conditions, business ownership and management structures. While much research in banking training has focused on claiming a relationship between training and firm performance, far less attention has been directed to understanding the association within the context of the organisation, its operating infrastructure and target market. Studies do not explain why some firms are more likely than others to invest in training. Some of the studies establish that organisational characteristics influence the training performance relationship, but they fail to include the contextual factors that influence the decision on training approach.

In Nepalese context, Pandey (2008) found that performance of the organization depends on the expectation of the employees from training. Most of the employees remain motivated by personal benefits. So, this study tried to see more in the context of training and performance relationship.

\section{Research Hypotheses and Methodology}

Given the foregone discussion, it is suggested that incidence (whether the firm engages in training), intensity (the number of training initiatives) and training approach (formal or informal), may affect organisational performance. In addition, the decisions on training approach will be influenced by contingent factors. 
Therefore, it is possible to consider that:

H1. Those banks that do provide training will perform better (in terms of turnover growth, business survival and employment growth) those that do not provide training.

H2. Higher intensities of training within banks will result in higher levels of turnover growth.

H3. Those banks that primarily invest in formal training will show higher levels of turnover growth than those that rely primarily on informal training.

Objective of this study is to find out the relationships between training and performance. It was found that the most appropriate methodology, and one that has been used substantially by other researchers (Huang, 2001; Westhead and Storey, 1996), was questionnaire survey. Although explanatory power is poor, the utilisation of a survey as a research methodology has been promoted by several social research literatures claming that it provides more robust results using more objective judgements during data collection and analysis (Alferd and Settle, 1995). It further provides greater confidence and a high external validity for the findings.

Likert scale questions were used for getting responses. One of the main focuses of the questionnaire was the list of formal and informal approaches to training. Officers were asked to state whether or not they had ever used a range of training techniques.

Ten commercial banks out of 29 were randomly selected from the population to ensure representation of all size categories. The questionnaires were sent to 250 respondents out of which 230 useable questionnaires were returned. The response rate is higher than in the previous similar studies. The questionnaire data was analysed using SPSS. Multiple regression analysis, ANOVA, and simple descriptive statistics were used for the data analysis. Regression analysis was used to see the relationship between training and firm performance. All training techniques taken individually and in group (formal, informal) were regressed on the dependent variable, turnover growth. ANOVA results were used to to demonstrate the significance of the moderating variables on the training-performance relationship.

\section{Measures Employed}

The study explores the combination of factors associated with the provision of seven types of formal training and five types of informal training. Respondents were given clear explanations, question items were translated into Nepali language to make them easily understandable. A separate category in each of the formal and informal training sections asked for other methods of training they provide in addition to the ones listed. These were incorporated into the relevant group by the researchers after consulting the respondents. Thus, data collection on the incidences of both formal and informal training was clear. Those respondents who have said no to both formal and informal training methods were included under the category NO 
training provision. To test the hypothesis that training can be associated with organisational performance, firm turnover growth was taken as proxy to firm performance. Employment growth and business survival, measured in terms of staff number increase/decrease and number of years of existence, were also regressed against independent training variables as performance measures.

When measuring the level of training associated with both informal and formal approaches, measures like training cost as a percentage of total sales (Cosh et al., 1998) and the number of employees being trained (Huang, 2001) were considered. This is because informal learning may be impossible to cost and individual learning efforts are unlikely to be recorded (Kitching and Blackburn, 2002). Therefore, three categorical variables were used to classify the training provision in the respondent organisations. First, organisations were classified into 2 groups according to whether they had undergone any training in the past. This variable was named as the incidence of training. A value of 1 was attached to organisations that adopted any of the training methods (formal/informal) and a value of 0 to organisations that had not used any training method at all. The second variable was the intensity of training, defined as the number of training methods in use by a firm. The average value for all the formal and informal training was calculated for organisations that had any training in the past. The third variable was labelled as the approach to training meaning whether formal or informal training received priority. For this analysis, organisations that had some training in the past were again divided into two groups. The training approach was set equal to 1 if the preferred training approach was formal and to 0 otherwise.

\section{Results Analysis}

\section{Intensity and Incidence of Training}

While there are a number of possible measures of firm performance, several authors (Jarvis et al., 2010) claimed that firm turnover growth is reliable. In testing the association between training and firm performance, turnover growth was therefore taken as a performance measure and the dependent variable in the regression analysis. The age of a business has often been linked to performance, and government policy objectives often include employment growth as a measure. Therefore, to provide a broader perspective on firm performance than is given in comparable studies, employee growth and business age were also included as performance variables. Measures were also included to control for multi-collinearity effects (Hair et al., 1984). First, to control for differences due to organisational size and the industry effect, the industry dummy and the measure of firm size were included in the analysis.

With respect to the turnover growth, we found a beta coefficient of 0.163 , which is highly significant $(p<0.01)$ for the incidence of training. However, the relationship between the number of training provided (intensity of training) and turnover growth was not statistically significant, although the patterns were in the predicted direction with firms that used more training initiatives reporting the highest turnover growth. This supports the notion that it is not necessarily the numbers of training provided to management team that increases the turnover growth of the firm. 
The highly significant coefficient for the firm size variable, for both incidence and intensity of training, indicates that there is a main effect of firm size on performance. Specifically, those firms with more staff were typically better performers than firms with less staff. Because of this, it was assumed that the relationship between training provision (both incidence and intensity) and turnover growth might be contingent on firm size. To check this moderating effect, the regression analysis included an interaction term (incidence/intensity of training $\mathrm{x}$ firm size). Although there is no relationship between the interaction term and performance with regard to incidence of training, there is a strong but negative association when intensity of training is taken as the training measure.

Using employee growth and business survival measures as performance variables provided some mixed results. In terms of employee growth (difference in employee numbers between the start of the business and now), we found a very strong significant association for both incidence $(\mathrm{t}=5.12$, sig. $<0.001)$ and intensity of training $(\mathrm{t}=2.81$, sig. $<0.01)$. When business survival (measured in terms of number of years of firm existence was regressed against incidence and intensity of training with firm size, turnover and industry type as control variables), we found a positive but insignificant relationship for the incidence of training $(\mathrm{t}=1.341$, sig. $=0.181)$, while for intensity of training, this association was negative and insignificant $(\mathrm{t}=-0.634$, sig. $=0.527)$.

\section{Formal and Informal Approach to Training}

Multiple regression analysis using two unordered sets of predictors were used to examine the relationship between formal and informal training on performance and to check whether firms investing predominantly in formal training better perform those relying on informal training. The regression results that while formal training has a significant relationship ( $p=0.000, \beta=0.251)$ to firm turnover growth, this relationship is insignificant and negative for informal training $(p=-. .231, \beta=.325)$. As these results hold true even under the control conditions imposed by firm size, age and industry, we can claim that formal training is associated with performance over and above informal training in banking organizations.

Furthermore, the very strong association found between turnover growth and firm size indicates that the relationship between the training approach and firm performance is contingent on the firm size. The results of the regression analysis when two interaction terms - formal training $\times$ firm size, informal training $\times$ firm size - were included as control variables. The training approach-performance relationship is contingent on firm size. While the firm size influence on formal training is positive and significant $(p=0.01, \beta=.211)$, this influence is negative and significant $(p=0.05, \beta=-.325)$ for informal training. Further analysis is required to test the significance of other possible moderators. We also investigated the relationship between employment growth and firm survival against the chosen training approach. When employment growth was regressed against average values for formal and informal training, we found very strong significant associations. While formal training had a positive and significant association with employment growth of a company ( $\mathrm{t}=5.48$, sig. $<0.001)$, this association was negative, but significant when informal training was considered as the dependent variable $(\mathrm{t}=-2.98, \mathrm{p}<0.01)$. 


\section{Moderators to Banking Training-performance Relationship}

The study included six variables that could potentially influence the firm decision on the most suitable training approach. Differences in training approach are significant for four of the six organisational characteristics considered in the analysis. Three of these, firm size, level of technology and business structure have a significant influence over the training approach decision at $p=0.001, p=0.007$ and $p=0.000$ and $\beta=.211$, .321 and .122 respectively, and were linked to formal routes of management development. The relationship between the business ownership (owner-managed and non owner-managed) and training approach remains significant at $\mathrm{p}=0.014$, with the owner-managed business showing more interest for informal training than the non-owner managed companies. Also there is no significant influence on the training approach with regard to firm age and level of innovation.

The mean difference in firm size, business ownership, level of technology and business structure of high performers using formal training versus informal training is significantly higher $(p=0.001)$ than the mean difference in these characteristics for low performers. Since the mean difference in age and level of innovation between firms using formal and informal training was significantly different, further comparisons were not relevant. Therefore, it is clear that the positive relationship were found between formal training and firm performance is moderated by a set of organisational characteristics. Companies with more staff, more structure, using advanced technology and those which are non-owner managed are in a better position to receive more benefits from formal training. Firm size and level of innovation are not significant determinants of the formal training-performance relationship.

\section{Discussion}

What is a particularly important contribution of this study is the finding that banking sector that conduct management training show a statistically significant advantage in terms of both employee and turnover growth, compared with those that either do not conduct training, or prefer to invest in informal training. It appears that the intensity of training (number of trainings) is only relevant for the firm's growth. This latter finding seems intuitive, since the number of training interventions required is likely to increase as staff numbers increase. It has been suggested in the literature ( Hill and Stewart, 2000; Kitching and Blackburn, 2013) that managers prefer informal to formal training interventions. However, while banking managers prefer an informal learning approach, this does not necessarily mean it is more effective. SFEDI (2004) note that it is important to distinguish between what is practiced (due to resource scarcity) and what is appropriate. In this research there is a clear and significant finding that formal training is associated with performance over and above that provided by informal training in small manufacturing firms. As with other studies, our findings are subject to criticisms of causal ambiguity (Storey, 2004). Also we must acknowledge that the measures of success used do not reflect the wide range of objective and subjective aspirations of banking managers (Curran and Blackburn, 2001). Nevertheless, the findings do add weight to the body of evidence on the training-performance relationship highlighted in earlier studies (Cosh et al., 1998; Marshall et al., 1995; Betcherman et al., 1997; Huang, 2001; Smith and Whittaker, 1999). 
There are a number of potential reasons that formal training may provide additional benefits over informal training. Firstly, there may be a lack of suitable skills - such as coaching or communication - within the firm to make the most of informal development activity (Hendry et al., 2010; Mabey and Thompson, 1994). Secondly, the owner-manager may be too busy to devote time to informal training. In this case when they recognise a staff development need they will utilise a formal approach that is cost effective in terms of their own time. In this case targeted formal interventions may be a chosen solution. This would accord with findings from Baldwin et al. (2015) who suggest that training targeted at a few key individuals is beneficial to banks' performance. Thirdly, previous research has highlighted training and development being utilised as a response to a problem (Blackburn and Kitching, 2008, Patton and Marlow, 2002), where "selecting training was particularly tailored to an identified training need" (Cassell et al., 2012).

When we look further into the statistics, these latter two points seem particularly relevant. The most positively significant approaches within formal training were the use of outside providers for in-house courses, and the use of in-house designed and delivered courses. Taken together with the finding that it is the incidence and not the intensity of training that will be important, this suggests that both of these types of intervention are likely to be used to target a specific and identified need: the former when specific skills or knowledge are absent, but the failure to address the skill need is perceived to jeopardize the business; and the latter when there is an ongoing skills need in the business that warrants training investment. The identification of this particular approach to invest in organizational knowledge adds weight to the findings of Cassell et al. (2012) and Hendry et al. (2010) that training is undertaken as tactical solutions to problems; the demand for training is explicitly related to improving the way the business is operated (Patton and Marlow, 2002). The intensity of training is less relevant, since generic interventions provide benefits to the individual and not the firm (Westhead and Storey, 1996). Given the difficulty of engaging bank managers who are under significant time pressures, attendance at seminars is likely to occur only when the information is considered relevant to a specific business issue. Thus, the most successful formal and informal interventions appear to be tactical solutions to crises, but, as such, they are likely to have a more direct effect on business performance. The idea that particular problems stimulate learning is highlighted in organizational learning theory (Weick, 1995; Fiol and Lyles, 1985) and has been identified by Cope (2013) as a particularly important mechanism to achieve higher-level learning in smaller firms. Our findings are also consistent with studies that conclude more flexible, targeted and relevant business support mechanisms are required in order to engage banking managers in development activity (Perren et al., 1999, Macpherson, 2015).

It is also interesting to note that the approach to training is moderated by contingent variables. In particular, this study highlights the influence of size (number of employees), structure, and use of technology on the approach to training chosen. Similar to findings by Reid and Harris (2012), researcher also noted that business ownership was influential, with non-owner managed companies significantly more likely to engage in formal training. Thus, this study also extends our theoretical knowledge of the contingency influence on the training-performance relationship. Perhaps more importantly, it has managerial implications in terms 
of designing and choosing the most suitable training approach for a particular context. However, in this regard the findings are only preliminary and further research is necessary.

There has frequently been a lack of coherence between the proposals made in theoretical studies and the focus of empirical work. While some research studied the association between training and organizational characteristics (Reid and Harris, 2012) others have examined the link between the amount of effort (budget/ time allocation) put on training and performance (Huang, 2001; Patton et al., 2000), and on management style (Sadler-Smith, 2004). Although these are complementary, none of the research considers these relationships within a multivariate framework. Thus, since our findings suggest that issues of structure, leadership and product/market seem to be influential in this relationship.

\section{Conclusions}

What is particularly important in this study is the finding that formal training is shown to be more significantly associated with performance than informal training. Moreover, while managers may perceive that informal training is more relevant, this study highlights the importance of targeted formal interventions to specific problems. Researchers suggest that these findings are consistent with tactical approaches to training that address specific and identified training needs. By addressing particular crises or difficulties, banking managers are investing (either time or money) to provide access to specific knowledge resources that can contribute directly to business performance. If they are to add value, need to be flexible enough to support idiosyncratic development needs, and not just provide generic solutions that do not accrue value to the firm (Jayawarna et al. (2006). Finally, the approach and effectiveness of training appears to be mediated by a number of contingent variables, including market, structure and leadership. Further analysis is required to provide a deeper understanding of these effects.

\section{References}

Alfred, N.J. and Settle, J.P. (1995). The measurement and antecedents of affective, continuous and normative commitment to the organization, Journal of Occupational Psychology, 63: 1-18.

Baldwin, F. R. et al. (2015). The relationship between training and organizational performance: a study in the health care field, Human Resource Development Quarterly, 12, 4: 335-52.

Betcherman, K. S. (1997). Notes on training evaluation, American Journal of Sociology, 66: 32-42.

Blackburn, S. and Kitting, W. (2008). Affective, continuance and normative commitment to the organization: an examination of construct validity, Journal of Vocational Behavior, 49: 252-76.

Becker, G. S. (1975). Human capital. New York: Columbia University Press.

Cassel, V. et al. (2012). How should we measure change - or should we?, Psychological Bulletin, 74: 68-80.

Cosh, J. et al. (1998). The effects of formal training on age of organization, Industrial Relations, 39, 4: 578-88.

Curran, M. and Blackburn, S. (2013). Peer observation, Innovation in Education and Training International, 35 (2): 171-76. 
Cushion, A.S. ( 1995). Personal and role related factors in the organizational performance, Administrative Science Quarterly, 18: 555-73.

Devins, F. and Johnson, K. (2003).Training effectiveness and organizational performance: a study of hospitality industry, Administrative Science Quarterly, 31: 1012-25.

Hair , X. et al. (2014). A review and meta-analysis of the antecedents, correlates and consequences of organizational performance, Psychological Bulletin,108: 171-94.

Hannon, F. (1999). Influences of individual and situational characteristics on measures of training effectiveness, Academy of Management Journal, 35,4: 828-47.

Hendry, K. et al. (2010). A role of moderating Variables on performance, Human Resource Management Review, 54, 1: 61-89.

Heraty, Y and Morley, S. (2003). Who benefits from training: big guy or small fry?, Development and Learning in Organizations, 27 (3): 213-27.

Hill, K and Steward, H. (2000). Training in the workplace: Theory, research, and application. Thousand Oaks, CA: Sage.

Huang, Y. (2001). The measurement of training effectiveness, Journal of Vocational Behavior, 14: 224-47.

Jarvish, W.R. et al. (2010). Trainees' attributes and attitudes: Neglected influences on training effectiveness, Academy of Management Review,11,4: 736-49.

Jayawarna, S. et al. (2006). Problematizing HRD in banking: a critical exploration of context, informalities and empirical realities, Human Resource Development Quarterly, 53(4) 156-170.

Jennings, P.L. and Banfield, P. (1993). 'Improving competence in banking organizations,' Journal of Applied Psychology, 78, 2: 291-302.

Kerr , K. and McDougall, F. (1999). Investigation of the factors that influence employee's participation in development activities, Journal of Applied Psychology, 86, 2: 391-402.

Kitching, O and Blackburn, A. (2002). Reward functions of personnel training, Human Relations, 42, 5: 373-78.

Marshall, F. (1993). The return-on-investment process: issues and trends, Training Journal, 1: 8-13.

Marshall and Ryan (2000). A longitudinal examination of the influence of mentoring or organizational performance, Academy of Management Journal, 48, 1: 158-68.

Noe, R. A. (1999). Employee training and development. Boston, MA: Irwin/McGraw-Hill.

Nunnaly, J.C. (1967). Psychometric theory. New York: McGraw- Hill.

O’Dwyer, E. and Ryan, B. (2002). How to Measure Training Results: A Practical Guide to Tracking the Six Key Indicators. New York: McGraw-Hill.

Pandey, D.L. (2008). Expected training benefits and organizational performance, Synergy, 1(1) 96-113.

Pant, P.R. (1983). Industrial relation in Nepal: A comparative study of public and private undertaking in the jute industry, India: Department of Public Administration, Punjab University.

Parren, K. (1999).' Individual differences and organizational climate', Personnel Psychology, 23: 493- 512.

Patterson, R. S. and Marlow, I. C. (1984). Gaining competitive advantage through human resource management practices, Human Resource Management, 23, 3: 241-55. 
Pradhan, G.B.N.(1992). Management education and training for public enterprises in Nepal, Administration and Management Review, 6: 103-12.

Reid, H. and Harris, B.E. (2012). Training \& Retraining: A Handbookfor Business, Industry, Government, and the Military. New York: Macmillan Reference.

Sadler, E.S. and Smith, A.J. (2004). The intuitive executive, Academy of Management, 10(1): 102-15.

Smith, A.J. and Whittker, J. (1999). Management training and development in small and medium sized enterprise. Journal of Small Business and Enterprise Development, 6(2): 215-32.

Storey, J. (2004). The Management of Innovation. UK: Edward Elgar Publishing.

Westhead, P. and Storey, J. (1997). Management training in small firms- a case of market, Human Resource Management Journal, 7 (2): 61-71. 